\title{
CONSTITUCIÓN Y DERECHO CONSTITUCIONAL EN LA UNION EUROPEA
}

\author{
JOSE LUIS CASCAJO CASTRO \\ Catedrático de Derecho Constitucional \\ Universidad de Salamanca
}

SUMARIO

I. Introducción

II. Breve indicación de algunas transformaciones de la democracia, el estado y la constitución como presupuestos del proceso de construcción europea.

III. Anotaciones sobre el llamado déficit constitucional y democrático de la Unión Europea.

IV. Estados y ordenamiento en la unión europea: una explicación necesaria.

V. En torno a la progresiva constitucionalización de la Unión Europea.

VI. A modo de epilogo.

\section{INTRODUCCIÓN.}

Hay momentos, y este parece ser uno de ellos, en los que resulta inexcusable reflexionar, aunque sea de forma oblicua, sobre algunas ideas básicas del propio oficio, tomando como pretexto el significado y alcance que supone la aprobación del Tratado por el que se instituye una Constitución para Europa. Sobre todo cuando uno lee, en el prólogo a un magnífico comentario colectivo sobre la nueva Constitución Europea, la siguiente propuesta, como estimulante envite: «Una constitución y un derecho constitucional sin Estado. Esta es la gran paradoja y el gran reto que presenta para los iuspublicistas de todos los campos el momento actual del proceso de integración europea» ${ }^{1}$. 
sirvió para extender la materia constitucional hasta amplios sectores de la realidad social y económica, favorecía también su posible extroversión más allá de los difusos límites de la actual forma política del Estado. No resultaba coherente seguir sosteniendo que los esquemas del constitucionalismo, tan benéficos en el orden interno, eran inaplicables justamente allí dónde empieza el mundo del derecho internacional, o no se podían extender al ámbito de emergentes organizaciones supranacionales.

La aplicación de lo que podríamos llamar el enfoque constitucional al análisis del proceso de integración europea, a juzgar por toda la doctrina vertida al respecto, no carecía de riesgos. Se ha podido hablar así de un exceso de «anhelo de Constitución» (G. Biaggini) que puede ser contraproducente en la medida que lleva a un empleo descuidado, a veces inflacionista del propio concepto de constitución.

A juicio de A. Pace es inexacto que el constitucionalismo provea de técnicas para la solución de cualquier problema nacional o internacional, siempre que tenga un relevante espesor político..$^{5}$ Insiste en que sus técnicas se dirigen a limitar funcional y estructuralmente el poder político o no es constitucionalismo. Y acaso no sea ocioso recordar estos planteamientos cautelosos, antes de aplicar todo un aparato conceptual, surgido en muy diversos contextos, al análisis del singular proceso de integración europea.

\section{BREVE INDICACIÓN DE ALGUNAS TRANSFORMACIONES DE LA DEMOCRACIA, EL ESTADO Y LA CONSTITUCIÓN COMO PRESUPUESTOS DEL PROCESO DE CONSTRUCCIÓN EUROPEA.}

Uno de los presupuestos de este proceso de construcción europea reside, sin duda alguna, en las transformaciones del Estado contemporáneo. Y una notable transformación es precisamente la existencia de un nuevo tipo de política, autónoma aunque en interacción con la política interior y exterior, que se proyecta sobre los fenómenos transnacionales, «cuyos actores son los Estados u organizaciones interestatales y/o las entidades transnacionales con la suficiente capacidad de recursos y de autonomía de acción para facilitar u obstaculizar la acción de los Estados o influir en sus decisiones» ${ }^{6}$.

Se ha insistido, desde muchos puntos de vista, en el proceso de entropía o de desorganización creciente del Estado, en tanto que institución histórica concreta (Garcia Pelayo). Múltiples factores y no sólo de orden económico pondrían en cuestión la unidad de acción y decisión del Estado. De manera que es fácil coincidir con K. Hesse cuando escribe:

1 Cfr. «El Proyecto de nueva Constitución Europea. Balance de los trabajos de la Convención sobre el futuro de Europa»,Enoch ALBERTÍ ROVIRA(Dir.),Eduard ROIG MOLÉS(Coord..), Ed.Tirant, Valencia 2004, dónde escriben también «que si los términos en que debe comprenderse la noción de Constitución en el ámbito europeo son originales y exigen un esfuerzo para adaptar las categorías existentes, y probablemente crear otras nuevas, no es menos cierto que su acción sobre las constituciones nacionales provoca la necesidad de abordar transformaciones novedosas en la propia concepción de la norma constitucional interna».

2 Cfr. A. MANGAS MARTÍN, «La Unión Europea y su futuro :el debate competencial», Noticias de la UE, 2002,p.81.

3 Cfr. RUBIO LLORENTE, «El constitucionalismo de los Estados integrados de Europa«, REDC, nº48. 
Para quien, como es mi caso, ha tenido que transitar modestamente desde el constitucionalismo histórico y comparado hasta el muy anhelado español vigente, tener que dar cuenta ahora de uno apellidado «europeo», por muy común que parezca, no deja de provocar una cierta sensación de perplejidad, además del obligado esfuerzo que supone acercarse a una realidad jurídico-política que no habíamos considerado, desde muchos aspectos, como propia, al menos los de mi generación. Acaso porque estábamos convencidos de que, como escribe una ilustre comunitarista : «la ingeniería constitucional para la original integración europea puede ser tan demoledora como la ingeniería financiera para la economía industrial» ${ }^{2}$. También porque éramos conscientes de que en el mejor de los casos, nuestro empeño no pasaba sino por analizar los innegables elementos constitucionales del proceso de integración europea, tarea distinta de aquellos juristas que de forma exhaustiva y monográfica habían configurado la doctrina científica del Derecho Comunitario, durante más de cincuenta años. Quede pues claro, desde el principio, que no pertenezco a la fraternidad del Derecho Comunitario, que diría Weiler, y que no pretendo por tanto invasión alguna en el terreno de estudio de nadie.

Ahora bien, no hace falta buscar ninguna excusa para considerar lo que representa un proceso de integración de Estados y de pueblos , cuya importancia es muy difícil de exagerar. Bien mirado, un mínimo ejercicio de responsabilidad intelectual exige, más allá de las diversas clasificaciones entre las disciplinas jurídicas e incluso del propio exceso semántico de adjetivación con que se apellida el nuevo Tratado, una cierta atención a tan complejo y singular proceso.

Tampoco es de extrañar que, dada la versatilidad del «constitucionalismo» y la densidad semántica del término «constitución», estos conceptos pudieran llegar a aplicarse en rigor a realidades que trascienden el habitual ámbito doméstico del Estado-nación. En todo caso ya no se podía seguir estudiando el Derecho Constitucional de los países miembros de la Unión, como si «el proceso de integración no implicase una transformación profunda del Estado, que obliga a reelaborar las viejas categorías y a crear otras $»^{3}$. Además, ni siquiera al constitucionalista de más rancia hechura le ha pasado desapercibido, a estas alturas, que el ordenamiento comunitario no se circunscribe a regular las relaciones entre Estados, con los instrumentos pacticios habituales, sino también las relaciones establecidas entre los ordenamientos estatales implicados en el proceso de integración y el propio derecho comunitario ${ }^{4}$. Tan patente resulta ya la propia dimensión europea del Derecho Constitucional que, según autorizada doctrina alemana, ha llegado a ser considerada como condición de la interpretación conforme a la Constitución.

La propia lógica del concepto racional-normativo de constitución, que en su día ya

4 Cfr. A. LA PERGOLA, «Il giudice costituzionale italiano di fronte al primatto e all' effetto diretto del diritto comunitario:Note su un incontro di studio»,Gir. Cost.2003,fasc.4,p.2420,dónde añade: «Quest'ultimo ordinamento, propio perché esso non rimane circoscritto ai rapporti internazionali,scende a disciplinare anche i rapporti interindividuali, e così genera i diritti di cui il soggetto privato fruisce come utente del mercato comune e, dal trattato di Maastricht in poi, come cittadino dell' Unione».

5 En un tono rotundo invoca la naturaleza prescriptiva y axiológica del constitucionalismo frente a concepciones omnicomprensivas del mismo. Afirma que implica una impostación metodológica siempre tensa para exaltar la limitación del poder y evitar así las arbitrariedades ,cuyo gran reto, hoy, es el de reencontrar y reafirmar su propia identidad originaria de teoría jurídica de los límites del poder político. 
dadanos y el Estado socava los mecanismos de representación y fomenta que el individuo se retire de la esfera pública» ${ }^{12}$. Apunta a un desplazamiento del paradigma social que iría de la idea de comunidad a la de red, como medio principal de interacción organizativa, de modo que el nuevo modelo de sociabilidad en nuestras sociedades se caracteriza por el individualismo en red, una red que se construye de acuerdo a las elecciones y estrategias de los actores sociales, sean estos individuos, familias o grupos sociales (M. Castells). Se describe el surgimiento de un Estado red global nacido de la cooperación entre gobiernos o de un Estado red emergente con su geometría variable de niveles institucionales y apoyos políticos, pero a juicio del sociólogo citado se siguen necesitando instituciones, representación política, democracia participativa, vías para la construcción del consenso y una política pública eficaz.

Uno de los mejores cultivadores, a mi juicio, de la actual Teoría Constitucional, el profesor J.J. Gomes Canotilho expresó con acierto otro de los presupuestos del cambio, referido en este caso al concepto de constitución: Incluso aunque las Constituciones continúen siendo simbólicamente la Magna Carta de la identidad nacional, su fuerza normativa tendrá que ceder ante nuevos fenotipos político-organizatorios, y adecuarse, en el ámbito político y en el normativo, a los esquemas regulativos de las «nuevas asociaciones abiertas de Estados nacionales abiertos» ${ }^{13}$. A juicio de este autor otra de las fragilidades epistémicas de un texto constitucional consistiría en su autismo nacionalista y patriótico.

Entre nosotros, R. Bustos Gisbert ha sintetizado muy bien la idea de pluralismo constitucional del profesor Walker al inventariar lo que podríamos llamar las críticas al viejo concepto de constitución y constitucionalismo ${ }^{14}$ : su vinculación al paradigma estatalista; la pretensión explicativa de todas las claves de la política por parte del derecho constitucional; la consideración de la constitución como sagrado centro del orden social y político; su carácter normativo homogeneizador respecto a las identidades de los ciudadanos y grupos sociales; la explotación ideológica de la constitución que va desde el contencioso por erigirse en el intérprete verdadero de la misma hasta cuestiones relativas a la imagen, símbolo y lenguaje de la constitución y finalmente la desfasada validez de algunos conceptos constitucionales, entre los que destaca el de pueblo, que ha sido objeto de un amplio y complejo debate ${ }^{15}$.

Ya con una cierta anticipación P. Häberle había estimado que la teoría constitucional debe afrontar de modo completamente nuevo el problema de si y en qué medida las constituciones nacionales constituyen ya solamente ordenamientos sectoriales de la «res publi-

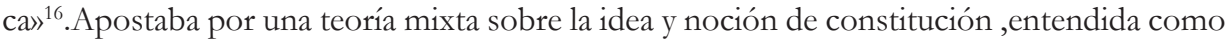
proceso público y cultura, funciones constitutivas estas últimas que cobran ahora una espe-

6 Cfr. M. GARCIA PELAYO, «Las Transformaciones del Estado Contemporáneo»,Alianza Editorial, Madrid,1977,p.158. Su fiable descripción sobre el fenómeno de la ampliación y restricción de la acción estatal vale, en mi opinión, para el supuesto europeo.

7 Cfr. «Estadios en la Historia de la jurisdicción constitucional alemana», en Teoría y Realidad Constitucional, no 6,p.119.

8 Cfr. S FABBRINI, «L'Unione Europea come democrazia composita?,Riv.It. di Sc.Pol.,2004,1,p.13 y ss.

9 Ult. op. cit. p.29.

10 Ult. op. cit. p.38. 
«Cuanto más pierde el Estado su carácter de forma histórica de gobierno introvertida y autosuficiente, más está llamada a incorporarse a Europa —es decir, con la Unión- y a desarrollarse conjuntamente con el resto de los Estados, que se sienten unidos no solamente por las exigencias de la economía (mundial) y la tarea de la procura de la paz, sino también por la cultura europea y los principios constitucionales comunes» ${ }^{7}$.

También desde la ciencia política se insiste en señalar que la Unión Europea(UE) es un sistema abierto, en constante transformación, con una estructura de gobierno «multinivel» organizada en torno a redes informales de actores privados y a veces públicos, que resulta difícilmente asimilable a los regímenes democráticos «internos» existentes ${ }^{8}$.Se quiere llamar la atención en que la propia lógica de funcionamiento de la UE es la de decidir sin el gobierno y en este sentido manifiesta su condición post-estatal. Y se la califica de «democracia compuesta» entendida como aquella dónde la soberanía está fragmentada y difundida a través de líneas institucionales y territoriales, lo que se traduce en una separación múltiple de poderes, desde el punto de vista institucional, y desde el funcional, en un proceso de toma de decisiones no monopolizable por una sola institución(el gobierno) ${ }^{9}$. La mayor dificultad en un tipo de democracia como la descrita es, precisamente, la de identificar las responsabilidades por las decisiones adoptadas. Al déficit democrático, parece que lógicamente irresoluble, de toda democracia compuesta, se uniría así el dilema de la responsabilidad ${ }^{10}$.

Los politólogos encuentran en Europa un desarrollado sistema de gobernanza supranacional y un elevado grado de multilateralismo, que no se encuentra en otros sitios. Pero mientras la esfera pública siga siendo principalmente una estructura nacional, la construcción de un tipo de democracia posnacional plantea graves cuestiones no resueltas ${ }^{11}$.Entre otras, la recordada por R. Dahl, de que el proceso democrático no está bien configurado para afrontar problemas de excepcional complejidad. Entra en juego también la función que incumbe al liderazgo político, que tan de manifiesto queda patente, a veces por su ausencia, en la experiencia europea en curso. No es tampoco de menor importancia, el alejamiento que experimentan los electores respecto a los límites y al control de las decisiones adoptadas por minorías cualificadas en el seno de la UE. Se ha escrito hasta la saciedad y con resultados muy desiguales sobre el denominado déficit democrático del proceso de integración europea, pero es fácil estar de acuerdo, al menos, en que se seguirá hablando de esta cuestión.

La literatura sociológica más solvente ha descrito también la crisis, no por manida menos cierta, de la legitimidad política, «en cuanto que la distancia creciente entre los ciu-

11 Cfr. Alberta M. SBRAGIA, «La democracia post-nazionale: Una sfida per la scienza política», Riv. It. di Sc.Pol., 2004, 1, p.43 y ss.

12 Cfr. M. CASTELLS, «La galaxia Internet»,ed. Areté, Madrid, 2001 ,p. 149.

13 Cfr. «Revisar o romper con la Constitución dirigente?. Defensa de un constitucionalismo moralmente reflexivo». REDC, $n^{\circ} 43$, p.14. Escribe también, al criticar las insuficiencias epistémicas de la «directividad constitucional», que «...elevar al Estado a único «director» implica un desconocimiento del alto grado de diferenciación de la estatalidad pluralísticamente organizada. Por otro lado,confiar al derecho la tarea de regular - y de regular autoritaria e intervencionísticamente- equivale a desconocer otras formas de dirección política que van desde los modelos regulativos típicos de la subsidiariedad, esto es, modelos de autodirección social estatalmente garantizada hasta los modelos neocorporativos,pasando por las formas de delegación conducente a regulaciones descentradas y descentralizadas. 
consecuencias necesarias de disposiciones incondicionales y precisas de una directiva, pero en cualquier caso se trata — según Le Monde (17.06.04) — de un acto de militancia europeísta, una especie de revolución jurídica e institucional, dos días después de unas elecciones europeas marcadas por la abstención, que se revela a contratiempo.

Se ha dicho también, desde la experiencia italiana, que el Derecho Comunitario se ha comportado como una especie de valor «paraconstitucional» respecto al ordenamiento jurídico nacional, alejándose o no entrando en la materia tratada por la norma comunitaria. Se trataría de dos ordenamientos coordinados pero distintos, dónde la expansión de uno se refleja automáticamente en la retracción del otro ${ }^{19}$. Esta fue una de las concepciones mantenidas por la Corte Constitucional italiana, sobre todo a partir de la llamada sentencia «La Pergola» ( $\mathrm{n}^{\circ} .170$ de 1984), que en el fondo suponía favorecer la integración. La cuestión es que no han pasado en balde veinte años ni para la jurisprudencia constitucional italiana, ni para la doctrina científica ni sobre todo para el propio desarrollo y evolución del Derecho Comunitario.

Hace tiempo que la doctrina científica había descrito, dentro de un contexto interactivo de pluralidad de ordenamientos, la «comunitarización» de los valores propios del constitucionalismo y la «constitucionalización» de formas y contenidos del derecho comunitario, como procesos circulares de mutuo recambio y alimentación ${ }^{20}$.

Pero en materia políticamente tan sensible como es la relativa a los modos de producción del derecho, este deseable encaje entre ordenamientos no dejaba de desdibujar los criterios formales de ordenación del propio sistema de fuentes y, en alguna medida, despertar los perennes resortes del dualismo: dos ordenamientos autónomos y diferenciados, aunque coordinados entre sí. Incluso hoy, hay quien sostiene que se trata de dos ordenamientos jurídicos diferentes, cada uno con su propia razón de validez; que la habilitación constitucional para la integración es, como todas las habilitaciones jurídicas, limitada; o que no se le puede permitir al legislador ordinario lo que se le niega al propio poder de reforma constitucional $^{21}$. Se muestra así, como ha dicho R. Arnold, una cierta reticencia a abandonar el núcleo mismo de la Constitución al poder comunitario.

Probablemente sea una cuestión, entre otras, de inercia mental la que impide al jurista desprenderse, en materia de fuentes, del principio de jerarquía. Si se define la constitución «como < derecho superior> y es esa superioridad la que justifica su misma existencia» ${ }^{22}$, no cabe en buena lógica ninguna otra normativa existente en el seno de la comunidad política que prime sobre aquella. «La calificación de constitucional de un texto supone que no podrá revisarse la corrección jurídica de su contenido a la luz de un texto superior, de existencia, por definición, imposible. Tal revisión, a priori o a posteriori, no sería lógicamente coherente con su carácter constitucional» ${ }^{23}$. Con tan ortodoxo concepto, y en previsión de lo que pudiera pasar, nos podemos curar en salud diciendo: «Claro está que una norma no tiene por qué ser coherente, y cabe perfectamente ( $y$ aún más resulta previsible)

14 Por generosa deferencia del autor utilizo el original inédito del libro sobre Constitución y Supraestatalidad, de inmediata aparición, dónde se aborda en profundidad esta problemática.

15 Cfr. S. DELLAVALLE, «Una costituzione senza popolo?, ed. Giuffrè, Milán, 2002.

16 Cfr. «Per una dottrina della costituzione europea», Quaderni Cost.,1999, nº1.

17 Cfr. P. HÄBERLE, «Europa como comunidad constitucional en desarrollo», en http://www.ugr.es/ ReDC1. 
cial importancia frente a la formación de los principios constitucionales europeos. Este conjunto de principios que proceden de las propias tradiciones constitucionales de los Estados miembros, tanto de su organización como Estados de Derecho cuanto de su propio derecho constitucional consuetudinario, además del propio Derecho Europeo surgido tanto de la UE como del Consejo de Europa, conformaría el llamado Derecho Constitucional común europeo, construido sobre la unidad cultural de Europa. Como es fácil advertir, se amplía considerablemente el objeto de estudio para el virtual «constitucionalista europeo», que se ve obligado a examinar una serie de ordenamientos jurídicos distintos, en relación con el suyo propio ${ }^{17}$,pero no de forma autónoma o separada sino como partes de un conjunto, que constituye un sistema.

\section{ANOTACIONES SOBRE EL LLAMADO DÉFICIT CONSTITUCIONAL Y DEMOCRÁTICO DE LA UE.-}

Resulta casi una obviedad repetir que el principio de legitimidad política en el Estado democrático constitucional reside en la soberanía popular. Pero es probable que de un entendimiento ontólogico y rígido de este principio, hayan surgido no pocas de las objeciones que se han vertido, sobre el llamado déficit democrático en la construcción europea. Además del lastre que supone seguir utilizando, a veces de forma inevitable, las categorías acuñadas para la histórica forma política del Estado, al análisis de una realidad que no es un Estado, ni tampoco está destinada a serlo.

\section{FUENTES DEL DERECHO.}

Para quien estaba habituado al manejo de nuestro sistema positivo de fuentes del derecho, resultaba de algún modo extraño y forzado, a pesar de la cobertura constitucional suministrada por el $\operatorname{art}^{\circ} 93$ de la constitución española (C.E.), esa especie de rango paraconstitucional que adquirían las fuentes comunitarias. Ahora, con ocasión del nuevo Tratado, P. Pérez Tremps sostiene que el marco constitucional interno de ratificación que supone el citado artículo 93 resulta insuficiente para proceder a esa ratificación...por lo que sería conveniente, e incluso necesario modificar la Constitución ${ }^{18}$.

Hace pocos años, dentro de una síntesis de respuestas al cuestionario Internet sobre el porvenir de Europa,¿Qué Europa en el 2010?, algunos expresaban dudas sobre qué lugar o rango ocuparía una Constitución europea en la jerarquía de las normas. Poco tiempo después, en una decisión del Consejo Constitucional francés, hecha pública el pasado 15 de junio, se reconocía la superioridad del derecho comunitario sobre el derecho nacional, al declarar por primera vez su incapacidad para declarar la compatibilidad de una directiva europea con la constitución francesa. Es cierto que acota esta «zona franca» reservada al control del juez comunitario, al supuesto de leyes francesas que se limitan a extraer las

18 Cfr. la obra citada en nota 1, p. 485 y ss. dónde puede verse en detalle toda la argumentación de la tesis mantenida.

19 Cfr. el vol. col. «I costituzionalisti e l’Europa», Ed. Giuffrè, Milán , 2002, p.535. 
a su juicio una operación de reforma constitucional previa, por el procedimiento agrava$\mathrm{do}^{29}$, «que de cobertura a la Unión Europea y que permita anclar interpretaciones «de compatibilidad» entre la Constitución española y Europea, en definitiva, que cubra lo que Rubio Llorente ha denominado el «déficit constitucional» de la integración europea, déficit que resulta insalvable para ratificar la Constitución Europea». Para F. Balaguer también «sigue en pie la cuestión de que ese «Derecho supremo» sea auténtico Derecho Constitucional, que ocupe el espacio que antes ocupaba el Derecho constitucional interno de los Estados miembros, con todas las garantías que le han sido inherentes en lo que a la realización del principio democrático y de los derechos fundamentales de los ciudadanos se refiere». ${ }^{30}$

A nadie se le escapa que de otro modo el propio instituto de la rigidez constitucional, elemento fundamental de autoprotección de cada ordenamiento, quedaría seriamente afectado . Por otro lado existe la razonable creencia de que la vigencia y el respeto del fundamental principio democrático ${ }^{31}$, encuentra mejor acomodo y tutela en el marco del ordenamiento nacional propio del Estado constitucional.

\section{PROCESO CONSTITUYENTE.}

Para quien está acostumbrado a entender el proceso constituyente como una serie de momentos que posibilitan a una comunidad política el planteamiento de sus propios fundamentos y el esfuerzo por clarificarlos, es posible que se sienta perplejo y desconcertado ante el proceso de construcción europeo, un proceso constituyente a su manera, irreversible y en marcha desde hace tiempo, basado más en el principio de efectividad que en los clásicos de legalidad y legitimidad con los que suele medirse la doctrina constitucionalista. Si se participa de la idea de que el momento constituyente no es más que un momento

20 Cfr. A. RUGGERI, «Continuo e discontinuo nella giurisprudenza costituzionale, a partire dalla Sent. N. 170 del 1984, in tema di rapporti tra ordinamento comunitario e ordinamento interno: dalla «teoria» della separazione alla «prassi» dell'integrazione intersistemica? En Giur. Cost. 1991. Más recientemente, R. TONIATTI, «Il principio di Rule of Law e la formazione giurisprudenziale del diritto costituzionale dell’Unione Europea», en el vol. col. "Costituzione italiana e Diritto Comunitario» a cargo de S. GAMBINO, Ed. Giuffrè, Milán, 2002, p.506, dónde escribe: «Vi è dunque, <in primis>, una dinamica endogena agli ordinamenti degli Stati europei - lo sviluppo omogeneo del propio diritto costituzionale interno- che rende possibile l'innesto di una dinamica esogena, ossia la trasposizione della prescrittività di singoli contenuti materiali della forma di Stato dal piano interno all'ordinamento comunitario (UE,CE) e internazionale (CdE), con sucesivo effetto di ritorno in direzione degli Stati».

21 Cfr. Christian HILLGRUBER, «La integración del Derecho Internacional y del Derecho de la Unión Europea en el ordenamiento constitucional alemán», en http:/ / www.ugr.es/ReDC1, dónde añade que el art ${ }^{\circ} 24.1$ de la constitución alemana no autoriza a renunciar a la identidad del ordenamiento constitucional vigente por medio de la ruptura de sus estructuras básicas, de sus estructuras constitutivas.

22 Cfr. L.LÓPEZ GUERRA, «El poder judicial español ante la Unión Europea», en Autonomies, n²9,2003,p.36.

23 Ult. Op. cit. p.52, dónde añade: « Si se mantuviera, pues, el carácter constitucional de la norma básica europea, y se aprobase como tal, no cabría ya en el futuro subordinar la fuerza vinculante de esa constitución europea a su adecuación a la constitución de cada país ni, por ello, cabría una revisión de las futuras reformas de la constitución europea por los tribunales constitucionales para verificar su adecuación a la norma constitucional propia». 
que se decida denominar «Constitución» o tratado constitucional a algo que no lo es» ${ }^{24}$.

La cuestión es, como ya se dicho con frecuencia, puramente nominalista. Puede ser cierto que el nuevo Tratado por el que se instituye una Constitución para Europa(TCE) sea una «constitución atípica que no responde a las características de una auténtica Constitución...» ni tampoco un Tratado en la medida que «a través de él se constituye (o se reconstituye) una entidad jurídico constitucional con sustantividad propia» (F. Balaguer). Quizás convenga hacer caso a los autores del estimulante libro colectivo, citado al comienzo de este trabajo, cuando nos recuerdan el deber de acostumbrarnos a ver cómo dos constituciones (si se prefiere una constitución bicéfala o dual) «conviven en un mismo territorio y regulan la convivencia política de comunidades dispuestas concéntricamente, y deberemos hallar las fórmulas y las categorías que permitan su compatibilidad y una convivencia razonable de ambas ${ }^{25}$.

Pero en cualquier caso y dejando de lado el intencionado y a veces ocurrente campo de las denominaciones ${ }^{26}$, ahora ya la sustantiva cuestión de la primacía encuentra lapidaria respuesta en el artículo I-6 del TCE.,que establece en su párrafo 1: «La Constitución y el Derecho adoptado por las instituciones de la Unión en el ejercicio de las competencias que le son atribuidas primarán sobre el Derecho de los Estados miembros».

En el ámbito de nuestra doctrina hay autores como Azpitarte que se preguntan si esa mención equívoca con el término Derecho en el citado precepto, incluye a las constituciones estatales, o es una muestra de que la raíz de la primacía no acaba de estar resuelta ${ }^{27}$.Y al margen de esta duda, metódica más que nada, acierta en mi opinión al destacar la dimensión política de la primacía, que le remite directamente a la cuestión, antes citada, de la supremacía constitucional, cuya razón de ser descansa, como es bien sabido, en la legitimidad político-democrática del momento constituyente propio de la norma fundamental. Contrastando con esta especie de axioma de la teoría constitucional, el autor citado se pregunta por el tipo de legitimación política sobre la que descansa la Unión Europea, y si tiene una legitimidad superior a las Constituciones nacionales. «La respuesta es demoledora: la Constitución europea se ratifica como un Tratado ( art $^{\circ}$ IV-8).Permítaseme el exceso, ¿no es esto una Constitución otorgada?».

Para P. Pérez Tremps el art.I-6 del TCE «está presuponiendo una posición de supremacía de la Constitución Europea sobre los ordenamientos internos, sin matizaciones, e incluidas, pues, las Constituciones nacionales, primacía que está en la esencia misma de la idea de Constitución $»^{28}$. Desde este punto de vista, resulta clara e insalvable la contradicción con el principio de primacía de nuestra constitución vigente ( $\operatorname{rrt}^{\circ} 9.1$ ), lo que exigiría

24 Ult. Op.cit. p.52.

25 Cfr. Op. cit. en nota 1, p.14.

26 La terminología y el lenguaje surgido para denominar la nueva realidad ha oscilado entre una carga simbólica destinada a subrayar la substancia política fuerte de la Unión y una cierta novedad y originalidad a la hora de bautizar a las instituciones y hábitos de la Unión. Cfr. «La Constitution de l'Europe»,ed. de P. MAGNETTE, Bruxelas, 2000,p.15. Recientemente F. BALAGUER, «La construcción del lenguaje jurídico en la Unión Europea», en http:// wmw.ugr.es/ReDCE1, ha insistido en esta cuestión, hablando de un «lenguaje anticipatorio»...de ir haciendo camino al andar...que junto a otros factores «han permitido acuñar un lenguaje jurídicopolítico propio...que representan singularidades derivadas de la forma en que se ha construido la Unión».

27 Cfr. «Las relaciones entre el Derecho de la Unión y el Derecho del Estado a la luz de la Constitución Europea», en http://www.ugr.es/ReDCE1. 
consecuencias dispares también a la hora de la rendición de cuentas a los correspondientes electorados. Aunque también en muchos supuestos cabe pensar, como ha repetido Weiler, que la relación entre la Unión y los Estados miembros no es del tipo de las de «suma cero»y por tanto el reforzamiento de la primera no significa necesariamente un debilitamiento de los segundos. Pero en todo caso, cabría siempre invocar el interés en la integridad del ordenamiento constitucional del Estado.

\section{ESTADOS Y ORDENAMIENTO EN LA UNIÓN EUROPEA: UNA EXPLICACIÓN NECESARIA.}

Según Weiler «estamos ante un orden jurídico constitucional en el que la teoría constitucional no ha sido aún desarrollada. En efecto, no ha habido una elaboración suficiente de sus valores trascendentes y de sus objetivos a largo plazo y se han interpretado mal sus elementos ontológicos $»^{33}$. Esta afirmación que no puedo calibrar bien, en su verdadero alcance, invita de todos modos a examinar una literatura doctrinal no carente de nuevos bríos y sobre todo de un distinto manejo de fuentes, puntos de referencia en ordenamientos poco frecuentados, etc., que supongo intentará colmar la carencia antes mencionada. A fin de cuentas, como ha dicho el autor antes citado, la discusión y la historia del constitucionalismo es también una historia y discusión intelectual de conceptualización e imaginación. Y pone como símbolo de estos nuevos aires doctrinales, siendo MacCormick la voz que le parece más autorizada, su ataque al prisma dualista de la tradicional imagen constitucional. Este enfoque dualista situa la relación Comunidad-Estados miembros en el centro del discurso y se apoya en gran medida en el principio de jerarquía de las normas, centralizadas y uniformes, en cuanto representación y solución del conflicto constitucional. Como contraste, la nueva doctrina reconoce y a veces sugiere una imagen diferente, «horizontal», «policéntrica», «infranacional», del sistema de gobierno europeo y de su estructura constitucional $^{34}$.

En esta línea de pensamiento insiste M. Poiares Maduro cuando afirma que la cuestión de quién decide quién decide «requiere una concepción del derecho que no dependa de una estructura jerárquica y una concepción de la soberanía como única e indivisible» ${ }^{35}$.

El propio Weiler se ha esforzado también en explicar el llamado principio de tolerancia constitucional, que a su juicio constituye una de las innovaciones constitucionales más importantes de Europa, y que en la práctica implica un acto de auténtica libertad y emancipación respecto a la arrogancia colectiva del propio ser y del fanatismo constitucional.

Es de sobra conocido que el debate académico sobre la esencia de Europa corre el riesgo de ser interminable además de bastante inútil, al menos para el jurista que busca una explicación suficiente a la actual situación. Acaso no sería más conveniente seguir siendo

28 Cfr. op. cit.p.495.

29 Cfr. op. cit. p.521 y ss. dónde se desarrolla la argumentación recogida de forma sucinta en el texto.

30 Cfr. «Fuentes del Derecho, espacios competenciales y ordenamientos jurídicos», REDC, n69, 2003, p.193.

31 Puede consultarse mi trabajo sobre dicho principio en la REDC, nº 69, Madrid, 2003. 
dentro de un proceso que está siempre abierto, el europeo ha tenido también sus particulares y heterodoxos momentos constituyentes, como pone de relieve la propia historia de la UE. Podríamos decir, forzando los límites de la analogía, que se ha ido implantando de manera original la fecunda semilla de un poder constituyente, no entendido desde los habituales modos de pensar del Derecho Constitucional.

Se ha acentuado por la doctrina el carácter dialógico y procedimental de este singular «proceso constituyente» del constitucionalismo europeo, manifestado a través de una voluntad de negociación y renegociación a lo largo de un «continuum» constitucional. En la concepción que del mismo ha elaborado Bustos Gisbert con rigor lógico, fuentes originales y bien aprovechadas de la doctrina anglosajona y en menor medida alemana, y no sin cierta audacia, se identifican en primer lugar actos de iniciativa que funcionarían como fuerzas performadoras causantes de cambios constitucionales y después una constitución evolutiva que se habría desarrollado a través de hitos constituyentes, entendidos como aquellos en los que una determinada comunidad, mediante diversos instrumentos y órganos proceden a articular progresivamente su modo de ser y de existir polícamente. A título de ejemplo menciona el citado autor, los momentos de modificación de los Tratados constituivos, acuerdos para la aceptación de nuevos miembros, determinadas decisiones judiciales del Tribunal de Justicia de la UE, decisiones inesperadas de los órganos de la propia UE,etc. A su juicio algunos de los avances en el proceso de integración europeo pueden ser analizados desde una teoría del cambio constitucional, que no requiere la presencia explícita del poder constituyente. «Desde esta perspectiva, la constitución europea sería un tipo de constitución de estilo británico. Una constitución que no ha sido creada en un acto conceptualmente único de voluntad del pueblo europeo» ${ }^{32}$. Llama poderosamente la atención, en el trabajo de Bustos Gisbert, su construcción del principio constitucional de apertura a la integración y cooperación internacional, en cuanto supone la asunción constitucional de las normas creadas en tales ámbitos de decisión, como consecuencia de un poder constituyente que se manifiesta a través de las ideas de legitimidad constitucional de origen, pacto entre entes post-soberanos y aceptación popular en el marco de procesos generales de diálogo constitucional.

Ahora bien, esta concepción abierta o integrada de la estatalidad como principio básico de la propia estructura, no deja de suscitar nuevos problemas. Se discute sobre cómo hacer operativo el circuito de la responsabilidad política en relación con el cuerpo electoral, al nivel supranacional, de modo que una cierta dirección política pueda embridar al proceso económico y social, que desde un esquema meramente funcional, no parece tener límites. De aquí surgen las quejas sobre la asimetría entre el poder comunitario en esta materia y las mermadas competencias concurrentes de los Estados miembros, con

32 Cfr. nota 14 de este trabajo. En el capítulo cuarto del citado original se desarrolla ,apoyado en la doctrina más reciente y novedosa sobre la materia, la cuestión relativa al concepto contemporáneo de Constitución ante la supraestatalidad. El tipo de constitución europea sería de las creadas poco a poco, «a través de un lento proceso de evolución inspirado en la solución pragmática y fruto del diálogo sobre problemas concretos y no del intento de reordenación global de la vida en común de los ciudadanos europeos» ... «una constitución que no supone una ruptura con el pasado»... «la llamada constitución europea no ha sido creada, ha crecido»...una constitución cuya parcialidad hay que entender no tanto como resultado de la carencia de un poder constituyente europeo, sino más bien como consecuencia de su peculiar método en el proceso de creación. 
había sostenido que este criterio era la clave realista de lectura de todo el complejo ordenamiento caracterizado por la supranacionalidad comunitaria ${ }^{42}$, dónde lo que se buscaba no era tanto la construcción de una organización jurídica cuanto la definición de un principio de lógica política capaz de componer el conflicto entre todos los poderes en presencia (supranacionales, estatales y subestatales).

La argumentación de Manzella, a mi juicio necesaria aunque no sé si suficiente, conduce a un tipo de Estado de soberanía autolimitada pero reforzado, con un nuevo rol como sujeto constitutivo del orden supraestatal comunitario y con la dimensión añadida que supone la dimensión comunitaria de sus funciones. También en el orden de los valores político-jurídicos este tipo de Estado «comunitario» desarrolla funciones de "pasarela» en un triple plano de prestaciones de unidad, legitimación y cultura ${ }^{43}$, poniendo a disposición del ordenamiento supraestatal sus propios recursos de «espacio público»,»representación política» y «ciudadanía»: "Contro l'ossessione di una democracia diretta europea, per colmare la presunzione di déficit vi è, insomma, il dato reale della democratizzazione dell’Unione attraverso gli Stati» ${ }^{44}$.

Como era previsible, el espléndido trabajo de A. Manzella que venimos comentando, remite también a la doctrina de R. Smend. En ella se puede entender la constitución como ordenamiento jurídico del proceso de integración y el Derecho Constitucional como un derecho de la integración. Es decir, un derecho de la unidad que no existe pero se realiza. Y se puede abandonar el concepto de soberanía ligado al Estado persona y a la vez abrirse al pluralismo social y político como factor de edificación del Estado, de manera que como ha dicho G. Zagrebelsk en su introducción a la versión italiana de la clásica obra del citado jurista alemán, «Constitución y Derecho Constitucional»,soberana es la integración como proceso en el ámbito estatal. Y para Smend la forma de la integración es un proceso en cuyo centro hay un consenso no una decisión.

$\mathrm{Al}$ ser el ordenamiento comunitario un tipo de ordenamiento que se basa en un proceso, desarrollado esencialmente en base a los principios del consenso, cohesión y ciudadanía, es perfectamente entendible desde los supuestos antes citados de la doctrina «smendiana», y configurable como una «red jurídica de comunicación interactiva», dónde se insertan los Estados como entidades abiertas y dinámicas ${ }^{45}$.

Cuando he calificado de necesaria la anterior descripción del proceso comunitario, en apretada síntesis, no he querido sino calificar una serie de posiciones doctrinales que me han parecido de gran valor explicativo. Ya se que en este campo se presentan arduos problemas de transferibilidad entre conceptos y no pocas dificultades de traducción, pero aún a riesgo de equivocarnos no podemos dejar de lado los notorios e importantes contenidos constitucionales que se van materializando en el camino por dónde transcurre el proceso de integración europea.

\section{EN TORNO A LA PROGRESIVA CONSTITUCIONALIZACIÓN DE LA UNIÓN EUROPEA.}

33 Cfr. Joseph H.H. WEILER, Europa, fin de siglo. C.E.C. Madrid, 1995, p.206.

34 Cfr. «The First Annual Journal of Common Market Studies Lecture:The Reformation of European Constitutionalism», en Journal of Common Market Studies, 35, 1997, 97.

35 Cfr. «Las formas del poder constitucional de la Unión Europea», en REP, n 119, 2003, p.34. 
fieles a la genial intuición funcionalista de origen, en vez de embarrancarse en la cuestión política e histórica de las formas de Estado, que bien mirada desde el corto plazo no deja de tener un cierto aire escatológico. Tal vez nos resulte más práctico abandonar los enfoques ontológicos de la morfología político- estatal (Confederación, Federación,...) y centrarse en la idea de una pluralidad de ordenamientos jurídicos, que siguen sus propias reglas de juego, dentro de un contexto dinámico y abierto por definición. Esta es la convicción de los autores que prefieren moverse no en el campo de la unión de Estados, sino en el terreno de la unión de constituciones, es decir de la unión de ordenamientos que tienen algunas instituciones comunes y otras complementarias, o si se prefiere subsidiarias.

En esta línea de pensamiento, se da cuenta de que el Estado auto-limita su propia soberanía a fin de crear con otros Estados un ordenamiento, dotado de poderes mayores que los de cada uno de los Estados que se asocian ${ }^{36}$.

No parece superfluo recordar en este punto a Santi Romano que ya consideró al Estado como uno de los ordenamientos jurídicos que constituyen el mundo jurídico, no el único existente, en base a los principios del pluralismo y la no exclusividad de los ordenamientos jurídicos ${ }^{37}$. Sin olvidar que para este gran jurista clásico un ordenamiento no es una suma de varias partes, sino una unidad en sí misma, distinta de los elementos materiales concretos que la integran ${ }^{38}$.

La doctrina científica ha descrito con todo detalle la singularidad del nuevo ordenamiento creado: legitimidad de origen en la soberanía de los Estados miembros, autonomía de ejercicio y desarrollo, impuesto tanto a los Estados como a los ciudadanos, superioridad normativa — formal y material — respecto de las normas de los Estados miembros, que al mismo tiempo funcionan como su presupuesto institutivo, indiferencia territorial y dualidad de estatus ${ }^{39}$.

A juicio de Manzella la legitimación de la citada operación de auto-limitación no comporta transferencia de la titularidad de poderes soberanos sino del ejercicio de los mismos y tiene un referente único en la soberanía popular, solo que se manifiesta de formas distin$\operatorname{tas}^{40}$.

Para Manzella el criterio de la subsidiariedad, entendido como «grundnorm» de funcionalidad del ordenamiento supraestatal (que se transfiere por la circularidad de los procesos europeos de ósmosis constitucional a los ordenamientos estatales) sólo puede justificarse por el monismo de legitimación de los distintos niveles de ordenamientos. ${ }^{41}$ Ya

36 Cfr. A. MANZELLA, «Stati e Ordinamento nell`Unione Europea», en el vol. col. «La constitución española en el contexto constitucional europeo», dir. Por F. Fernández Segado, Ed. Dikynson, Madrid, 2003, p. 401 y ss.

37 Cfr. SANTI ROMANO, «Principii di Diritto Costituzionale Generale», Ed.Giuffrè, Milán, 1947, p.59, dónde insiste en la idea de que hay evidentemente tantos ordenamientos positivos cuantos cuerpos sociales en los que se concretan.

38 Cfr. SANTI ROMANO, «El Ordenamiento Jurídico», Instituto de Estudios Políticos, Madrid, 1963, p.96, dónde argumenta con un rigor impecable sobre las posibles relaciones entre ordenamientos jurídicos estableciendo el concepto de relevancia jurídica de un ordenamiento respecto de otro, en los siguientes términos: «... para que haya relevancia jurídica es necesario que, o la existencia, o el contenido, o la eficacia de un ordenamiento determinado, estén condicionados respecto de otro ordenamiento, y ello precisamente en base a un título jurídico», p.249.

Para el lector español que no esté muy habituado al manejo de la doctrina italiana conviene indicar que esta obra fue escrita por ROMANO en la segunda década del siglo pasado.

39 Cfr. op. cit. nota 35, p.402. 
valores compartidos de la U.E.(Weiler), o ayudándose de la noción de ciudadanía de geometría variable, basándose en diferentes factores subjetivos de identificación (A. Pérez-Luño), que dan lugar a múltiples lealtades concéntricas. A cualquier constitucionalista le resulta muy difícil exagerar la potencia integradora que lleva consigo el instituto de la ciudadanía europea, dada la lógica tendencialmente universal de los derechos fundamentales y libertades públicas. Como ha dicho Ferrajoli la igualdad y garantía de los derechos son condiciones necesarias y suficientes para la formación de la única «identidad colectiva» que vale la pena conseguir:la que se funda en el respeto recíproco.

Para la mentalidad acostumbrada a examinar la parte orgánica de los textos constitucionales, la regulación institucional de la U.E. sigue pareciendo un ingenioso cuadro de conjunto, que busca un equilibrio entre el órgano intergubernamental y el órgano parlamentario, el centro y la periferia, los poderes de la U.E. y los de los Estados miembros, etc.

Sorprende a quien haya seguido mínimamente el esfuerzo de integración y legitimación que han experimentado los órganos de la jurisdicción constitucional en el seno del organigrama del actual Estado democrático y constitucional de Derecho, la envidiable autonomía y el acatamiento al razonamiento jurídico del Tribunal de Justicia de la U.E., «como voz incorpórea de la justa razón y de la teología constitucional» (Shapiro), aunque uno sepa de su decantada jurisprudencia sobre Tratados institutivos de organizaciones internacionales, utilizando sistemáticamente criterios propios del Derecho constitucional (L.M. Diez Picazo). No ha resultado sencillo la asimilación en el ámbito de nuestra cultura jurídica, sobre todo para aquella más anclada en viejos esquemas, de todas las consecuencias que implica la positivación constitucional de un órgano como el Tribunal Constitucional,

40 Una es la forma propia de las constituciones nacionales y otra es la forma de los procedimientos de decisión propios del ordenamiento supraestatal : «In questa seconda prospettiva si realizza nei relativi processi giuridici un esercizio di sovranità basata su quell'unione sempre più stretta tra i popoli dell'Europa (art ${ }^{\circ} 1$ TUE) $^{\prime}$ che dal punto di vista giuridico, se non socio-politico, costituisce il «popolo europeo». È in esso la base di legitimacione democratica di decisioni che valgono per tutti e per ognuno i popoli associati. Sia che la legitimaciones si attui attraverso il controllo dei rispettivi governi statuali (per il loro agire nell'ordinamento sovrastatuale); sia che essa si attui mediante rappresentanza política in assemblee parlamentari sovrastatuali; sia che essa si concretizzi in attivazione di strumenti giurisdizionali per la tutela dei diritti della sfera sovrastatuale», op. cit. p.403.

41 Para el autor que venimos siguiendo no hay piedra filosofal del catálogo de competencias, no hay contralímites a las limitaciones de la soberanía, no hay funciones estatales inalienables, no hay cláusulas de intangibilidad para el ordenamiento supraestatal respecto a la soberanía de regulación de los Estados nacionales...pero distinto es el argumento sobre la «soberanía de la institución». Llega así al problema central de la autoconservación institucional del Estado. Vid. op.cit.p.406.

42 Cfr. del mismo autor, «La ripartizione di competenze tra Unione Europea e Stati membri», en Quad. Cost. $2000, n^{\circ} 3$, p.534. A su juicio la unidad del ordenamiento comunitario se funda pues sobre un principio procedimental que permite interconectar los ordenamientos nacionales al ordenamiento supranacional, en un espacio consorcial de participación y de decisión. Esto supone la creación de instituciones transversales entre la Unión y los Estados miembros de forma que garanticen la efectividad.

Además la subsidiariedad exige las responsabilidades nacionales por el mantenimiento de todo el conjunto, creando una tensión nueva y desconocida por la autarquía estatal. «In questa configurazione ad incastro, discende il radicale superamento del principio della ripartizione di competenze per attribuzione, propio per la difficoltà concettuale di separare istituzioni sovranazionali e istituzioni nazionali rispetto alle finalità dell 'Unione»,op.cit. p.542.

43 Cfr. el trabajo de MANZELLA citado en nota 35, p. 410.

44 Ibidem, p.411. «Si verifica dunque nello spazio giuridico europeo un importante fenómeno di legittimazione popolare per connessione $\mathrm{di}<$ costituencies $>$...l' introvabile demos europeo è in realtà un «popolo-dielettori». Se extiende a continuación en refutar dos errores teóricos recurrentes recogidos en la fórmula del déficit democrático y en la de la doble legitimación, vid. p.412 y ss. 
Quizás una de las tareas del constitucionalista en este campo sea la de controlar teóricamente los esquemas del Estado de Derecho, del Federalismo, o de la Ciudadanía, a los que haya podido adecuarse el propio ordenamiento comunitario en su evolución. A otros le corresponderá analizar los sucesivos estados de ánimo que desde el euro-optimismo al europesimismo pasando por el euro-escepticismo, junto con otras variables, son sin duda datos relevantes para el análisis político y social. Se recomendará incluso una cierta calma, al pensar que ha llevado siglos la formación de naciones en contraste con el poco tiempo transcurrido para la formación de un casi-demos a escala europea (V.Pérez-Díaz). Se aconseja pues dar densidad a la experiencia vivida, corta en nuestro caso, de «ser europeos», de un nuevo espacio público, de la movilidad de los ciudadanos, etc..

Tampoco es igual la óptica desde la que se aborde tan magno y complejo proceso. Porque una es la perspectiva de la crónica europea, tan maltratada entre nosotros y sin embargo tan importante como medio de formación y expresión de una opinión pública a escala europea; otro es el trabajo de la esforzada doctrina científica dedicada al análisis sistemático y operativo de un sinfín de actos normativos y administrativos, resoluciones judiciales y procedimientos de todo tipo que integran el derecho europeo y otro es el punto de vista propio de la proyección institucional, para el cual, el jurista — especialmente el de corte dogmático si es que alguno queda - no parece estar especialmente dotado. Un magnífico ejemplo de esta última clase de enfoque viene representado por el conocidísimo discurso pronunciado por J. Fischer el 12 de mayo del 2000, en la universidad Humboldt de Berlín, aunque como ya nos advirtiera D. Grimm la anticipación institucional ,en esta materia, no puede ser excesiva.

Baste para la ocasión mencionar algunos de los rasgos más familiares a nuestras categorías y esquemas habituales de análisis.

Como es bien sabido el TUE sancionó el acostumbrado canon gradualístico en la construcción del orden institucional europeo. El gradualismo se asocia, por otra parte, a los principios de subsidiariedad y proporcionalidad en relación a la conducta de la Unión misma, que no puede penetrar en la esfera dejada a los Estados miembros, cuando alguno de ellos está en condiciones de perseguir eficazmente con sus propios medios los objetivos establecidos en el Tratado.

No deja de ser un importante hallazgo el consagrar en un pacto de unión, situaciones subjetivas del individuo con las garantías que le proporcionan los principios del constitucionalismo. Proporciona una vinculación entre pueblos y no sólo entre Estados. Supera el doble criterio de la movilidad y la no discriminación en los respectivos territorios entre ciudadanos autóctonos y foráneos. Confía su tutela jurisdiccional a la jurisprudencia comunitaria: reconocimiento al individuo de derechos garantizados, todos con igual título, como fundamentales para todo ciudadano. El propio «status» europeo del individuo, que no es sino la raíz de un más profundo sentido de la unidad europea, puede ser visto también como un proceso progresivo de construcción a través de la institucionalización jurídica de la comunicación entre ciudadanos (Habermas), o como parte integrante de un pueblo, entendido como el conjunto de ciudadanos de distinta nacionalidad, comprometidos con los

45 Citando a De GIOVANNI entiende el conjunto supraestatal-estatal como un «conjunto soberano» que «dà forma ad una esistenza política non più colta nella forza di un unico soggetto, ma in una molteplicità connessa e regolata, eppure in definitiva «una»,perché esistente como <novum>». 
para dejarlas en manos de los juristas. ${ }^{46}$

Para mí ha sido más bien la ocasión de tratar, de forma un tanto oblicua como decía al comienzo de este trabajo, sobre la orientación actual del Derecho Constitucional, contestando de modo un tanto peculiar y tardío, a la encuesta planteada en el $\mathrm{n}^{\circ} .1$ de esta Revista. También en el trabajo académico, como ocurre en otras facetas, suele importar más el camino que la meta, y en este sentido algo hemos hecho entre todos los constitucionalistas, de distintas generaciones, para facilitar y explicar la senda común, recorrida en estas tres últimas décadas.

Hace un año, también escribí, un escueto apunte en forma casi aforística sobre la noción e idea de la constitución, que he pretendido ahora, con estas líneas, continuar. Permanezco en la convicción, más firme si cabe, que toda auténtica constitución se apoya en un orden de valores y que su apertura a instancias supraestatales no sólo no hay que verlo como un riesgo sino que supone un corolario lógico de la anterior afirmación. Porque un mínimo realismo obliga a lamentar que el constitucionalismo no pueda por sí mismo garantizar sus presupuestos ni imponerse por encima de las constrictivas razones de la actual estructura económica mundial, pero no exige que al menos se aspire a que no haya ámbitos exentos, dónde puedan ir extendiéndose sus frutos. En el laboratorio europeo se ha podido ir verificando, empíricamente, la anterior afirmación. Mientras tanto, y en medio de la terrible crisis de las clases políticas de la sociedad actual, nada mejor que darse una pausa para la reflexión sobre cuestiones fundamentales, y ganar tiempo para un debate constitucional que proceda a una indagación de la forma del mundo(Slöterdijk). 
y por eso a la hora de fijar el principio de relaciones entre Cortes Supremas siempre manifiesta uno fundadas cautelas.

Quizás por el hábito hermeneútico de aplicar el principio de unidad de la constitución, cuesta la interpretación en un ordenamiento estratificado, «en el que pueden identificarse varios modos de funcionar de la palabra Constitución» (Cruz Villalón), porque puede suponer una cierta idea de ruptura para quien está habituado a los dogmas de completitud, coherencia y unidad del ordenamiento constitucional positivo vigente.

También conocemos la dificultad aneja a una delimitación precisa entre jurisdicciones, pero no es esta una razón para dejar de buscar un diálogo cooperativo entre la jurisdicción constitucional y la comunitaria, que indefectiblemente acabará produciéndose.

Como nos ha enseñado mejor que nadie A. La Pergola, al escribir sobre el Federalismo por analogía, resulta operativo también el principio de la cohesión socio-económica, que materializa una política social y regional, a través de los fondos estructurales, gestionados por programación integrada. La analogía con la experiencia del «New Deal» es patente, al margen de la carencia de un adecuado centro de gravedad institucional de las actividades de programación, que debería situarse en el seno de una autoridad comunitaria legitimada democráticamente.

Estas son, entre otras, algunas de la cuestiones que nutren el Derecho constitucional común europeo, como ponen de relieve las publicaciones ya muy numerosas sobre la materia. Pero quisiera entender que este deslizamiento constitucional hacia el ámbito europeo no es sólo un fenómeno de moda, realizado sin brújula ni método, al puro dictado de los acontecimientos de un tiempo presente, cada vez más precario e insustancial si se me permite la expresión.

\section{A MODO DE EPILOGO.-}

Como he escrito recientemente, para los constitucionalistas no va a suponer poca fatiga enfrentarse, desde nuestras habituales categorías dogmáticas, con un tipo de texto jurídico como el que ha sido presentado al Consejo Europeo reunido en Salónica el pasado 20 de junio del pasado año. Pero esta es una excusa insignificante al lado de lo que puede representar el paso de la aprobación del TCE, en el proceso de construcción europea.

Se ha dicho con acierto que hablar de cultura es o termina por ser lo mismo que hablar de religión. El debate habido a propósito del Preámbulo del TCE así lo pone de manifiesto. No es este un campo en el que quepan verterse banalidades y menos aún simples ocurrencias, ni tampoco acceder a él sin conocimiento de causa.

En esta ocasión, baste con invocar la obra del gran poeta T.S. Elliot sobre la unidad de la cultura europea, dónde, entre otras muchas y valiosas ideas, insiste en la íntima relación que hay entre religión y cultura, incluso en las sociedades más conscientes y evolucionadas; identidad que permanece incluso a un nivel inconsciente.

Para quien como Weiler ha enseñado que el constitucionalismo es como un prisma para observar un paisaje de un determinado modo, un artefacto académico con el que se organiza los elementos de un paisaje y una construcción intelectual para dar significado a lo que se observa, debe resultar también natural debatir sobre cultura y religión a propósito del TCE. Por eso piensa que es ridículo ocuparse de la civilización europea sin reconocer la centralidad del cristianismo, recordando a la vez que ¡es una constitución «europea» lo que estamos construyendo! y que se trata de cuestiones demasiado importantes como 
46 Cfr. «Una Europa cristiana», ed. Encuentro, Madrid, 2003, pp. 55 y 56. 